\title{
Los militares en el Perú: Entre el pasado inmediato y el futuro mediato
}

\author{
The military in Perú: Between the recent past and the mediate future
}

${ }^{1}$ Jaime M. Taype Castillo

\section{RESUMEN}

Las Fuerzas Armadas del Perú han vuelto a tener protagonismo. Esta vez, no por causa de un conflicto bélico o amenaza terrorista, sino para combatir, al lado de médicos, enfermeras, biólogos, químicos y personal de limpieza, a la pandemia provocada por el COVID-19. No es la primera vez que los militares peruanos participan en un suceso que compromete la vida del ser humano, esto se puede apreciar en los últimos 50 años de nuestra historia republicana.

Palabras clave: Desastres naturales, Fuerzas Armadas del Perú, multipropósito, nuevos roles, pandemia.

\section{ABSTRACT}

The Peruvian Armed Forces have once again played a leading role, not because of a war or terrorista attack, but this time, to figtht a pandemic by Covid 19, alongside doctors, nurses, biologists, chemists and personal cleaning. I was not the first time that the peruvian military participated in an event that compromised human life, as can be seen in the last 50 years of our republican history.

Keywords: Natural disasters, Peruvian Armed Forces, multipurpose, new roles, pandemic.

\section{INTRODUCCIÓN}

A partir de la segunda quincena del mes de marzo de 2020, fueron movilizadas nuestras Fuerzas Armadas a nivel nacional para desempeñar la protección y control de la población peruana, al declararse Estado de Emergencia, el mismo que derivó en el "Aislamiento social" que buscaba aminorar los efectos causados por la pandemia del "COVID-19" que, semanas atrás, venía propagándose en diferentes puntos del planeta.
En ciudades y comunidades, particularmente para los más jóvenes, les resultaba novedoso ver de cerca o por medio de las pantallas del televisor o celular, el desplazamiento de vehículos de las Fuerzas Armadas con efectivos militares, quienes en las principales vías o centros de gran concurrencia solicitaban los documentos correspondientes a los ciudadanos que transitaban, recordándoles que debían retornar y permanecer en sus hogares por su seguridad.

${ }^{1}$ Teniente EP. Instituto de Estudios Históricos del Ejército del Perú. Universidad Nacional Federico Villarreal. Lima-Perú.

E-mail:jmtc2012@hotmail.com

Presentado: 04/04/2020, Aprobado: 16/05/2020 
¿Estábamos en guerra? Era paradójico que un virus, solo perceptible al lente de un microscopio, fuera capaz de paralizar al mundo, encerrar a los seres humanos en sus viviendas, colapsar los servicios sanitarios y movilizar a las fuerzas militares. Probablemente, en la historia contemporánea, Adolfo Hitler u Osama Bin Laden no provocaron tanto temor como sí lo estaba haciendo este virus.

En nuestro país, a pocos días de iniciarse la cuarentena por causa de la epidemia, el Jefe del Comando Conjunto de las Fuerzas Armadas del Perú, general César Astudillo Salcedo manifestaba en una conferencia de prensa:

"[...] tendremos bajas que lamentar, son usos de la guerra [...] pero vamos a vencer. Todos están en alerta, en esta guerra, que la vamos a ganar [...]. Yo solo le pido a nuestros jóvenes, que ahora cuiden a sus abuelos y sus padres [...]. Ellos los cuidaron de niños, cuídenlos ustedes ahora. ¿Cómo? Quedándose en casa" (Canal N, 21 de marzo 2020).

En medio de este periodo de aislamiento, existieron algunos casos de comunicadores sociales y "especialistas" que, aprovechándose de incidentes aislados, trataron de deslegitimar la labor de las instituciones castrenses, particularmente del Ejército, apelando a calificativos de "gorilismo" y "no estar preparados" para este tipo de situaciones (Salazar, 2020), incluyendo cuestionamientos por el empleo de expresiones considerados "belicistas" de quienes participaban en la primera línea combatiendo al COVID-19 (La República, 21 de abril 2020).

Este hecho ponía una vez más en evidencia aquello que ha sido calificado como el tradicional "divorcio" entre civiles y militares en nuestro país (Masterson, 2001 , p. viii), motivados por determinados acontecimientos históricos, animadversiones o posturas políticas, percepciones o simplemente, por el desconocimiento de la labor que cumple el otro, entre otros elementos que en conjunto han influido en la relación civil-militar (CAEN, 2010).

Ante esta coyuntura mundial ¿El Ejército del Perú -en particular- volvía a tener protagonismo en sucesos no bélicos a partir el fenómeno de El Niño Costero del 2017? La historia y la realidad afirmaban que no, ya que los soldados (término que engloba tanto a los oficiales, técnicos, suboficiales y los jóvenes que prestan hoy su Servicio Militar Voluntario en el Ejército) no solamente habían actuado en conflictos externos o ante el accionar de organizaciones terroristas, en los casi dos siglos de vida republicana.

Estos también intervenían cuando la población era sacudida por un gran movimiento sísmico, ante el desborde de un río e inclusive hoy, prestaban apoyo a quienes por un error humano, sufrían la pérdida de un familiar o bien material.

El presente artículo, enfocado desde el tipo opinión, busca mostrar las acciones no militares desarrolladas por el Ejército del Perú durante los últimos 50 años en el país, teniendo como marco la reciente epidemia producida por el COVID-19; a través de los cuales observaremos la importancia de contar con una fuerza militar, no solo para la defensa de su soberanía, sino también para el socorro de su propia población ante desastres naturales o pandemias, como ha quedado evidenciado en la actualidad.

Para ello, se han revisado fuentes producidas por la propia institución castrense, el Ejército, a fin de conocer desde sus acciones no militares, casi siempre desapercibidas entre las investigaciones existentes. Aquellas fuentes pueden convertirse en nuevos elementos para futuras investigaciones históricas que comprometa la participación de los militares peruanos, no necesariamente en sucesos políticos o bélicos.

\section{Militares peruanos: De lo "Tradicional" a los "Multipropósitos"}

En esta parte del continente ¿Desde cuándo los militares colaboraban con la población afectada por los desastres provocados por la naturaleza? Se tiene registros que, tras el terremoto y maremoto que destruyó la ciudad de Lima y desapareció al presidio del Callao con sus casi 5 mil habitantes (entiéndase "presidio" como ciudad o puerto amurallado) la noche del 28 de octubre de 1746, el entonces virrey ordenó la movilización de su milicia para poner 
orden entre la población que reiteradamente caía en la desesperación producto de las réplicas sísmicas y la falta de alimentos (O'phelan, 2003), así como por los actos de pillaje que se presentaron en la capital aprovechándose de la tragedia (Pérez - Mallaina, 2001).

En tiempos ya republicanos, particularmente los terremotos no desaparecieron -ni desaparecerán-, aunque este tipo de amenaza no es la única que afecta la tranquilidad de los peruanos. No olvidemos que entre los desastres naturales figura el fenómeno de El Niño, el mismo que habría influido en parte a la desaparición de los Mochicas alrededor del año 650 D.C (Fagan, 2009); además de los huaycos en determinados lugares y meses del año, entre otros. Ya en el siglo XX, durante el Oncenio de Augusto B. Leguía (1919-1930) el senador por Junín, Augusto Bedoya a comienzos de 1920, agradecía y felicitaba la labor del Ejército a través del Batallón de Colonización $\mathrm{N}^{\circ} 19$ en favor de la población de Tarma, que se vio afectada por las inundaciones producto de las intensas lluvias (OGE, 1920). Más adelante, a partir de la segunda mitad del referido siglo, "Nuevos Roles" serían asumidos por la fuerza militar.

¿Por qué desempeñaban este tipo de labor las Fuerzas Armadas, particularmente el Ejército? Una publicación de la referida institución, señalaba que "El Ejército pertenece a la nación y por lo tanto no puede permanecer sordo ante el clamor de nuestros compatriotas, ni mucho menos ante los problemas del país, sobre todo tratándose de situaciones de emergencia [...]" (Campos, 1983, p. 10).

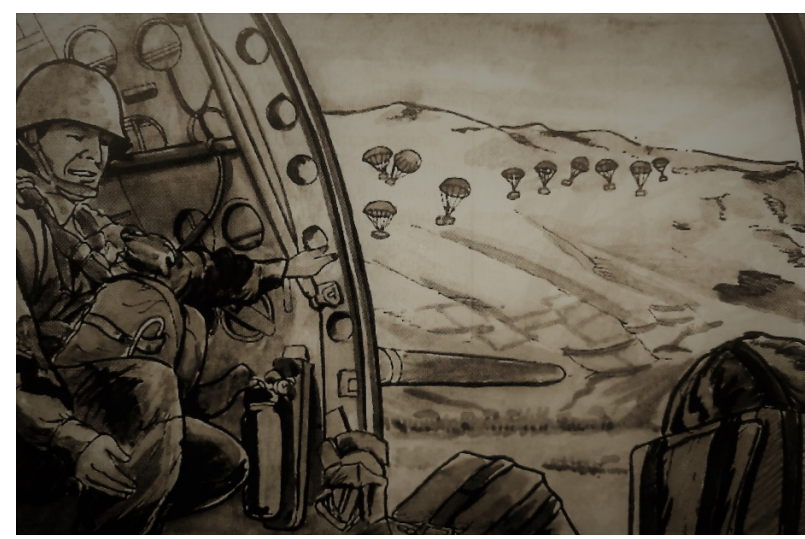

Figura 1: Grabado del lanzamiento en paracaídas de alimentos, abrigos y medicinas sobre pueblos por el terremoto de mayo de 1970, en Ancash. Fuente: "El Ejército del Perú frente a los desastres naturales".
La labor de apoyo hacia la población peruana, ante los desastres naturales, siempre ha sido constante por parte de las Fuerzas Armadas, apoyando a las instituciones sanitarias y de Defensa Civil, a razón de su presencia a nivel nacional, re-direccionando los recursos humanos y materiales con los que cuenta. Si bien en la actualidad, se ha redactado las normas para su empleo ante situaciones no bélicas; no obstante, dicha labor ya venía realizándose con anterioridad.

\section{[...] las Fuerzas Armadas y la Policía Nacional del Perú, participan en la preparación y respuesta ante situaciones de desastre y actúan de oficio en la atención de situaciones de emergencia que requieran acciones inmediatas de respuesta, realizando las tareas de urgente necesidad que les compete, aun cuando no se haya declarado el Estado de Emergencia (Páez, 2013, pp. 173-174).}

Es por eso que, las Fuerzas Armadas que se conciben en este nuevo siglo son aquellas denominadas "multipropósito" o "multi-misiones", donde sus funciones ya no se abocan solo a la defensa de la soberanía nacional -que no debe ser descuidadoa y es el principal fin de los ejércitos del mundo- sino que a su vez cumplen "nuevas misiones", como se ha podido apreciar ahora frente al Covid-19.

\section{Los "Nuevos Roles": Entre el ayer y el mañana}

En relación a la labor que cumple el Ejército ante situaciones no bélicas y que compromete de igual manera la seguridad de la población, veamos algunos ejemplos ocurridos en los últimos 50 años.

Al respecto, entre los meses de marzo y abril de 1965, personal del Ejército apoyó a la población de Tumbes afectada por las intensas lluvias, construyendo canales para el desagüe de aguas estancadas; el reforzamiento de las riberas del río Tumbes y la evacuación de personas, enseres y animales de las zonas vulnerables a las inundaciones (RAM, 1965).

$\mathrm{Al}$ año siguiente, el 17 de octubre, un fuerte sismo remecía Lima, Callao y la zona del "Norte Chico", provocando la muerte de aproximadamente 100 
personas y cuantiosas pérdidas materiales (Giesecke, Silgado, 1981). Ante ello, el Ejército se movilizó para ayudar, atender a los afectados y remover los escombros, a través del Batallón de Infantería Paracaidista "3 de octubre" N $\mathrm{N}^{\circ} 39$ y la División Blindada del Rímac (RAM, octubre 1966).

Pero uno de los sucesos más trágicos que conmocionó al Perú y al resto del mundo fue el terremoto y alud que sepultó la ciudad de Yungay (Ancash) con la mayoría de sus habitantes, el 31 de mayo de 1970. Y es menester recordar este suceso, ya que en el 2020 se conmemora los 50 años de ocurrida la tragedia.

Las ciudades ancashinas de Huaraz, Caraz y Yungay fueron destruidas no solo por acción del movimiento. En efecto, a pocos minutos y como consecuencia del terremoto, parte del glaciar central del nevado Huascarán se desprendió, provocando un gran alud que sepultó a los pocos segundos las localidades de Ranrahirca y Yungay (Espinoza, 2018).

En este último, solo sobrevivirían 2 mil de los más de 20 mil habitantes, al conseguir refugiarse en la parte alta del cementerio de la localidad, incluyendo a un grupo de niños que asistían a una función circense en momentos que ocurría la tragedia (RAM, 1970).

Enterado de la situación, el entonces Presidente de la República General Juan Velasco Alvarado se reunió inmediatamente con su gabinete y a las 23:00 horas del mismo 31 de mayo, zarpó de la base naval del Callao a bordo del BAP Bolognesi con dirección al puerto de Chimbote, a fin de dictar las medidas necesarias en la misma zona afectada. "[...] En Chimbote, el general Velasco dictó las disposiciones del caso para iniciar las tareas de auxilio y el planeamiento de la reconstrucción. Lo notable [...] es la prontitud con que se tomaron las disposiciones y se movilizaron todas las fuerzas nacionales" (Taype, 2015, p. 71).

El mandatario sobrevoló la zona afectada en un helicóptero de la Fuerza Aérea del Perú (FAP), no pudiendo aterrizar por la polvorera que la cubrían. Ante ello, el gobierno emitiría el comunicado oficial $\mathrm{N}^{\circ} 38$ que ponía en marcha la "Operación Socorro" con que nuestras Fuerzas Armadas se encargarían de socorrer a los damnificados, convirtiéndose Chimbote en el Centro de Operaciones de Emergencia (Espinoza, 2018, p. 33).

Al quedar los poblados del Callejón de Huaylas incomunicados, fueron 100 paracaidistas del Ejército del Perú los primeros en saltar y llegar a la zona del desastre, llevando ayuda para los sobrevivientes, dando inicio a la referida operación (Taype, 2015). Finalmente, un Batallón de Ingeniería de Construcción permanecería en la zona hasta 1975, en las afueras de Caráz, apoyando la construcción en una zona más segura, de la nueva ciudad de Yungay. Por la labor desarrollada, aquel batallón del Ejército fue denominado luego como BIC “Huascarán” N 112 (CPHEP, 2001).

Pero además de los terremotos y aludes, otra de las amenazas es el fenómeno de El Niño, que ha acompañado al Perú durante su historia. Entre las recientes y más destructivas figuran las ocurridas en 1983 y 1998, que afectaron particularmente la costa norte (MAE, 1983).

Una vez más, la falta de previsión y de organización por parte de las autoridades políticas y de la propia población para mitigar los impactos negativos y aprovechar los positivos que traía el fenómeno, agravaron el desastre. Las pérdidas materiales y humanas reflejaban como el desconocimiento y la ausencia de preparación magnifica las consecuencias de un fenómeno natural (El Comercio, 2000, p. 74).

Además de las cuantiosas pérdidas sufridas en Piura y Tumbes, los efectos de El Niño 1982-83 se extendieron al SE del Perú. En Puno ocurrió una severa sequía que hizo perder cosechas enteras y produjo la muerte del ganado. El impacto sobre la economía nacional fue desastroso en 1983 (Kuroiwa, 1999). Ejemplo de ello fueron las pérdidas en la industria de harina de pescado por 10 millones de dólares, así como de 42 millones de dólares en algodón y el azúcar (Klarén, 2011) 


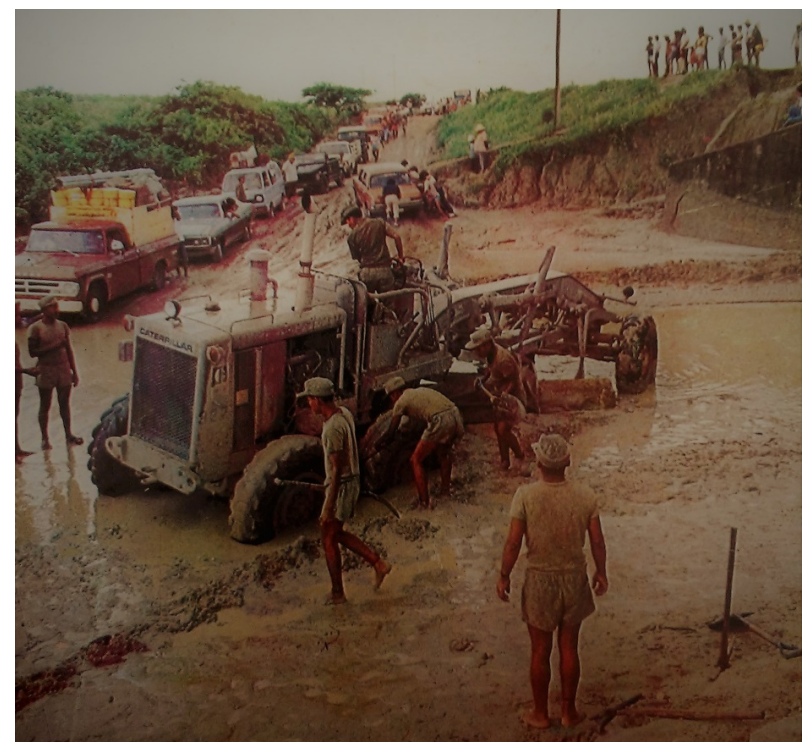

Figura 2: Personal del Ejército limpia las vías afectadas por el fenómeno de El Niño, 1983.

Fuente: Revista Actualidad Militar, 1983.

En medio del caos y la tragedia producida por el fenómeno, el gobierno de Fernando Belaunde Terry dispuso la movilización del Ejército para el socorro de la población, desplegándose las unidades móviles, de ingeniería militar, sanidad militar y personal de tropa.

[...] donde hay necesidad de un puente, de restablecer el tendido de cables, de rellenar zanjas, de rehabilitar carreteras, dar seguridad, allí están los efectivos militares con tractores, motoniveladoras, cargadores frontales trabajando en forma ininterrumpida (Campos, 1983, p. 10).

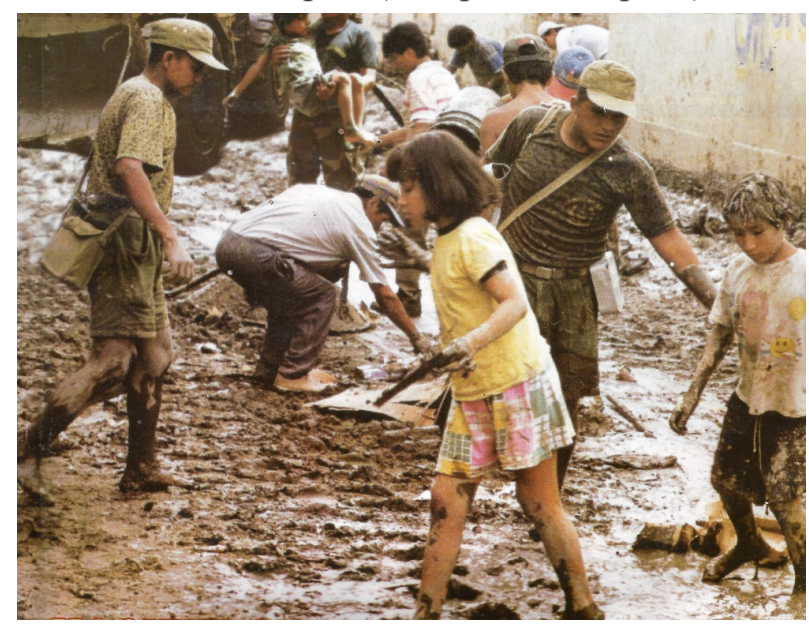

Figura 3: Soldados ayudando a población del norte del país afectada por el fenómeno de El Niño, 1998.

Fuente: Revista Actualidad Militar, 1998.
Similar situación se repetiría quince años después. Nuevamente el Ejército, quien paralelamente desde la década de 1980 venía enfrentándose a las organizaciones terroristas autodenominadas Sendero Luminoso y Movimiento Revolucionario Túpac Amaru (este último protagonista de un prolongado secuestro en la residencia del embajador del Japón en nuestro país, que culminó con una exitosa operación militar de rescate en abril de 1997) (Wicht y Rey de Castro, 1998), así como haber enfrentado y expulsado a las tropas ecuatorianas infiltradas en suelo peruano en 1981 y 1995; se movilizaban ahora para socorrer a sus connacionales en diferentes puntos del país, esta vez amenazados por acción de la naturaleza, siendo la más afectada la costa norte (CPHEP, 2017).

Las unidades militares del Servicio de Ingeniería del Ejército (SINGE) apoyaron con equipos y maquinarias (tractores, volquetes, cargadores frontales, equipos de iluminación, comprensoras, entre otros), rehabilitando las zonas afectadas por el fenómeno de El Niño de 1998 (RAM, 2016, p. 46). "[...] el Ejército fue movilizado para socorrer, llevando ayuda médica, y reconstruyendo carreteras y puentes que habian colapsado producto de las continuas lluvias en 1998" (RAM, 1998, pp. 14-18). No obstante, en marzo de 1994, personal militar colaboraba con los damnificados del Callao afectados por el desborde del río Rímac, en las zonas de Gambetta y Sarita Colonia. Así mismo, trabajó en el reforzamiento de la ribera del referido río (MAE, 1994, p. 273).

Posteriormente, en junio del 2001, efectivos del Ejército apoyaron a las poblaciones de las regiones de Arequipa, Moquegua y Tacna afectadas por un fuerte sismo. Similar actuación tendrían tras el terremoto en agosto 2007, que provocó daños en las poblaciones del Sur Chico (Cañete y Chincha) y la región Ica.

Frente a esta trágica situación y por disposición del Comando Conjunto de las Fuerzas Armadas (CCFFAA) entrarían en funciones el Comando de Operaciones del Centro, de directa responsabilidad militar [...] dispondría la inmediata movilización del personal de la Primera Brigada de 
Fuerzas Especiales del Ejército y de la $18^{\mathrm{a}}$ Brigada Blindada [...]. Más de dos mil efectivos, entre oficiales, técnicos, suboficiales y personal de tropa, llegaron a la zona de desastre para brindar apoyo y seguridad [...] (Taype, 2017, p. 57).

Tres años después, durante el mes de enero, la Aviación del Ejército empleando sus helicópteros evacuaba a pobladores y turistas de las localidades cuzqueñas de Calca, Quispicanchi, Cuzco ciudad, Urubamba, Canchis, La Convención y Anta, que quedaron aisladas por las intensas lluvias (CPHEP, 2017).

Sabemos que las inundaciones causadas por el desborde de los ríos o por intensas lluvias, así como los deslizamientos de tierra o "huaycos", se presentan de manera casi anual en la zona de Chosica (Lima) y en otros puntos del país, como ocurrió en las localidades de Constitución y Chanchamayo; Ayacucho (2011); Huánuco (2013); San Luís de Shuaro y centro poblado Pampa Toro (2014); Ilabaya-Mirave, en Tacna (2015); sismo en Arequipa (2016), El Niño costero (2017), entre otros. En todos ellos participó el Ejército colaborando de la mano con la población (CPHEP, 2017).

Es un riesgo permanente ser un país altamente sísmico. La población está habituada a sufrir los embates de terremotos, inundaciones y desprendimiento de glaciares, entre otros desastres. Una vez ocurrido, se recurre a la solidaridad para ayudar a reparar los daños causados y paliar la desazón, volviéndose a la normalidad según la efectividad de las gestiones que siempre adolecen de prevención(Chiabra, 2010,p. 304).

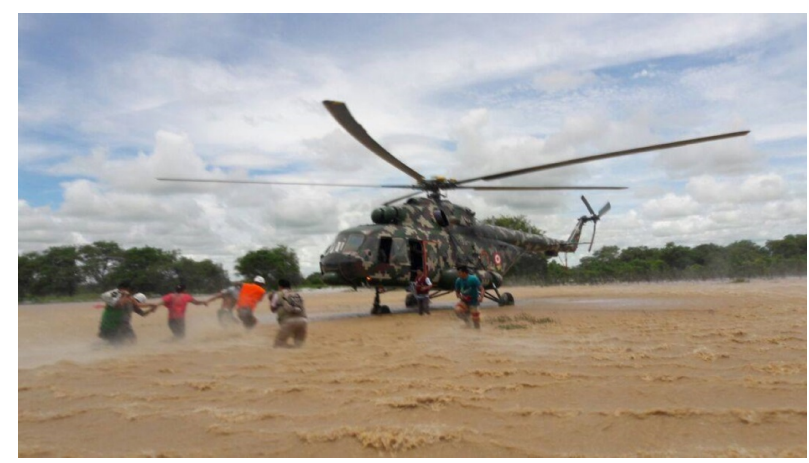

Figura 4: Evacuación de población afectada por el Niño Costero, 2017 en helicópteros militares.

Fuente: Oficina de Informaciones del Ejército.
Respecto a los sucesos anteriormente mencionados, debemos señalar que en noviembre del 2012, el entonces Presidente de la República del Perú declaraba que "en este nuevo siglo, las Fuerzas Armadas del Perú cumplen -además de las funciones tradicionales- los también conocidos como Nuevos Roles que son tan igual de peligrosas como las guerras"(CPHEP, 2017, p. 9).

Entre las amenazas tradicionales destacan la expansión territorial de los países vecinos o extra continental en prejuicio de nuestra soberanía, terrorismo, desastres naturales comunes, entre otros (CAEN, 2010).

Sobre lo anterior, la misión de socorrer a la población ante los efectos de los fenómenos naturales forma parte de lo que se conoce hoy como los "Nuevos Roles" o nuevas misiones que vienen siendo asumidas por las FF.AA. para hacer frente a las "Nuevas Amenazas", destacándose en esta última el cambio climático y sus consecuentes desastres naturales que ponen en riesgo la vida e integridad del ser humano (provocados con mayor intensidad y de manera reiterada por acción de la alteración climatológica), así como las epidemias y enfermedades de origen natural o por intervención de la mano del hombre, entre otros (CAEN, 2010).

En los años más recientes, la $1^{\text {a }}$ Brigada Multipropósitos y las Compañías de Intervención Rápida Contra Desastres (CIRCD) creadas por el Ejército, han socorrido a la población tacneña afectadas por los deslizamientos de lodo y piedras ocurridas en Mirave (2019), Alto de la Alianza (2020), así como en las localidades de las regiones de Moquegua y Cuzco, esta última por causa el desborde del río Salkantay (2020). A ello se suma el apoyo a los damnificados del distrito de Villa El Salvador (Lima) afectados por la fuga y explosión de GLP de un camión (RAM, 2020).

\section{Misión militar y colaboración de la población}

Los párrafos anteriores han hecho un breve recuento general de las principales acciones desarrolladas por el Ejército en el país durante los últimos 50 años ante los desastres de origen natural o humano.

Además de las anteriores, también se desarrollan de manera simultánea las Acciones Cívicas ejecutadas por la referida institución castrense en las comunidades más apartadas y de escasos recursos económicos, que son beneficiadas con las campañas gratuitas de salud, asesoría jurídica, educación, entre otros, y cuyo análisis merecerían otro artículo (Taype, 2015). 


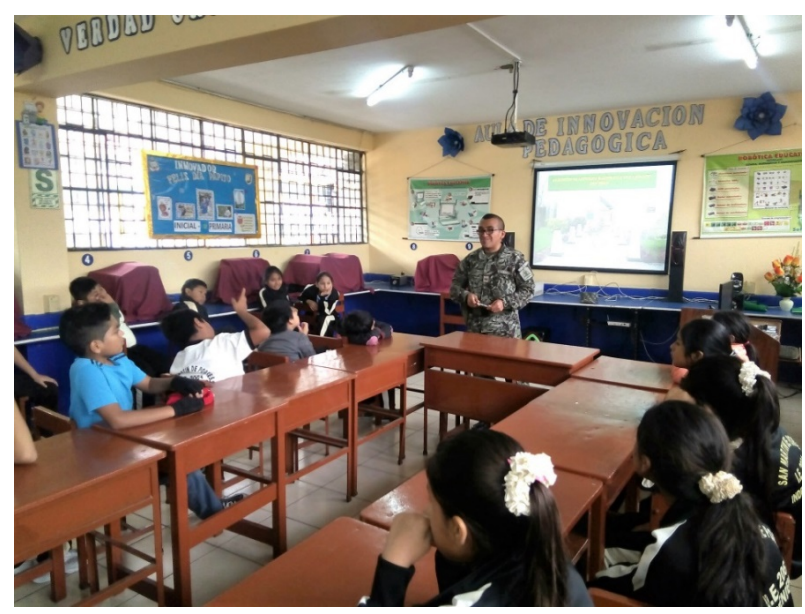

Figura 5: Clases gratuitas impartidas por oficiales del Ejército en instituciones educativas del país, 2018. Fuente: Instituto de Estudios Históricos del Ejército del Perú.

Pero a pesar de estas acciones de los militares en favor de la población; no obstante, no han sido ajenas las tensiones entre los segmentos civiles y militares que conforma la población peruana.

Entre las principales causas de aquella discordancia figura el Servicio Militar Voluntario (SMV) y su intento en tiempos recientes de que retornase a ser "Obligatorio" (SMO). Recordemos que el reclutamiento entre los jóvenes en edad militar en nuestro país fue obligatorio hasta el año 1999, cuya Ley al ser modificada, hizo que ésta se volviera en una prestación voluntaria (COREMOVE, 2016).

Sin embargo, entre los años 2012-2013 se generó en la opinión pública peruana -particularmente en Lima- un gran debate a razón que el gobierno de entonces propuso el retorno del Servicio Militar esta vez bajo el mecanismo por sorteo. Por un lado, la manera como las autoridades impulsaron el proyecto, abundó en falencias; pero por la parte de la población, particularmente entre los jóvenes, llamó la atención su movilización oponiéndose a la propuesta gubernativa, apoyados por la mayoría de la prensa, colectivos ciudadanos y ONGs, así como algunas autoridades y personajes políticas que no dudaron en jugar en contra de la propuesta castrense, buscando sacar réditos políticos (Taype, 2019).

Los argumentos opositores giraban desde la actuación de los militares frente a la violencia terrorista en las décadas de 1980 y 1990, incidiendo particularmente en el gobierno de Alberto Fujimori (a pesar que los involucrados han enfrentado procesos judiciales y cumplen condena por sus acciones), pasando por la supuesta "violación" a los derechos humanos de quienes fueran seleccionados por el referido sorteo, y culminando con la propuesta de quienes señalaban de que el Servicio Militar debía ser remunerado (Taype, 2019).

Esta última propuesta promovía, quizás involuntariamente, un ejército mercedario que en tiempos de guerra resulta siendo inútiles para la defensa de un pueblo, como en alguna oportunidad lo manifestó Nicolás Machiavello en su obra "El Príncipe".

[...] Las mercenarias son inútiles y peligrosas $[\ldots]$ son ambiciosos y no guardan disciplina ni fidelidad: valientes entre los amigos, cobardes en presencia del enemigo [...] No sirviendo estas tropas sino por el interés de un corto salario que nunca equivale al riesgo de perder la vida, sólo sirven con gusto en tiempos de paz, y luego que se declara la guerra retroceden ante el enemigo o desertan [...] (Machiavello, 2002, p. 156).

Sobre lo anterior, no significaba que el soldado no recibiera una prestación económica, que si lo tiene y es conocida por los no militares como la "propina". Lo que se buscaba era hacer entender que la prestación del Servicio Militar era un deber que debía ser cumplido por el joven en edad militar, sin que sea visto como una pérdida de tiempo o motivado sólo por un interés económico, más aún en esos años donde el SM ya contaba con diferentes beneficios, incluyendo las oportunidades educativas. Era evidente una vez más, el desconocimiento por un importante sector de nuestra sociedad del reclutamiento por sorteo aplicado en numerosos países, inclusive entre nuestros vecinos.

Sin embargo, ninguno de los opositores al proyecto de Servicio Militar por sorteo reflexionó o tuvo en cuenta -al parecer- de la coyuntura internacional que por entonces comprometía a nuestro país (la demanda por la delimitación de la frontera marítima con el vecino país del sur y que generó maniobras militares preventivas en ambos lados de la frontera terrestre). Esta actitud de cierto sector de la población, reflejaba lo expresado por el general José del Carmen Marín Arista -fundador y primer director del Centro de Altos Estudios Militares, hoy CAEN- hace más de cincuenta años atrás. 
Parte de los ciudadanos creen expresar ese repudio a la guerra y esa tendencia pacifista, oponiéndose a las medidas de defensa, y la mayoría de los restantes son totalmente indiferentes ante ellas, creyendo que el cumplimiento de sus deberes al respecto se limita a tomar las armas cuando la patria se haya en peligro y que mientras no haya guerra nada tienen que hacer" (Taype, 2018, p. 77).

Al parecer, nadie recordaba la historia de los conflictos del que fuimos participes, particularmente de la falta de unión, animadversión a lo castrense e intereses políticos y particulares que se presentaron antes, durante y después de la guerra de Chile contra el Perú (1879-1883). Quizás en pleno comienzo del siglo XXI, determinados sectores de nuestra sociedad, por desconocimiento o influenciados sutilmente por intereses ajenos a nuestro país, mantenían aquel "negacionismo" y "animadversión a lo militar" que en alguna oportunidad acusó el historiador tacneño Jorge Basadre, docente por entonces de la Escuela Militar de Chorrillos.

La generación a la yo que pertenecí en mis años de estudiante [...] fue ella un producto genuino de la Edad de la Negación en la que el Perú ha vivido durante mucho tiempo, y recibió más de una vez con silbidos y denuestos al hombre uniformado que pisara las aulas universitarias (Basadre, 1943, p. 247).

Finalmente, la propuesta del Servicio Militar por sorteo no prosperó, como consecuencia de la fuerte presión mediática y la ejercida por un sector de la población. Si bien la contienda diplomática en la Haya no devino en un conflicto bélico; sin embargo, la necesidad de contar con un número necesario de efectivos militares -particularmente entre quienes prestan el Servicio Militar Voluntario- saldría nuevamente a la luz, años después.

En tales errores incurren aún personas de elevada cultura $[\ldots]$ cuando se les habla de defensa nacional, la identifican innecesariamente con la idea de guerra $[. .$.$] .$ Partiendo de esta confusión y del hecho objetivo de que las Fuerzas Armadas son las que realizan la guerra, fácilmente llega a la errónea conclusión de que sólo a estas incumbe preparar la defensa nacional (Taype, 2018, p. 77).
¿Y porque se toca el tema del Servicio Militar en medio de desastres naturales y pandemias? Esto obedece a razón de la percepción de un sector considerable de nuestra sociedad que considera que lo militar esta únicamente vinculado con la guerra, lo que es un craso error. Culminado la demanda internacional con los resultados ya conocidos en el 2014 ¿ya no tenía sentido mantener un ejército con numerosos soldados? La respuesta esa pregunta apareció recién casi 7 años después, no por causa de una eminente contienda bélica, sino por la amenaza de una pandemia que ponía en jaque la salud de nuestro país junto con el resto del mundo.

La carencia de visión prospectiva por parte de las autoridades políticas hacia el futuro, y el desconocimiento por parte de la población respecto a la necesidad de contar con unas FFAA equipadas tanto con recursos materiales y humanos para el mejor cumplimiento de las múltiples misiones que le asigna el Estado, quedaron evidenciadas al momento de enfrentar al COVID 19 en el Perú. Entiéndase al Estado como aquel "cuerpo" conformado por la población, el territorio y el poder político (CAEN, 2010 , p. 14), precisión necesaria ante las reiteradas ocasiones de confundir "Estado" con "Gobierno", tanto por la población y sus autoridades.

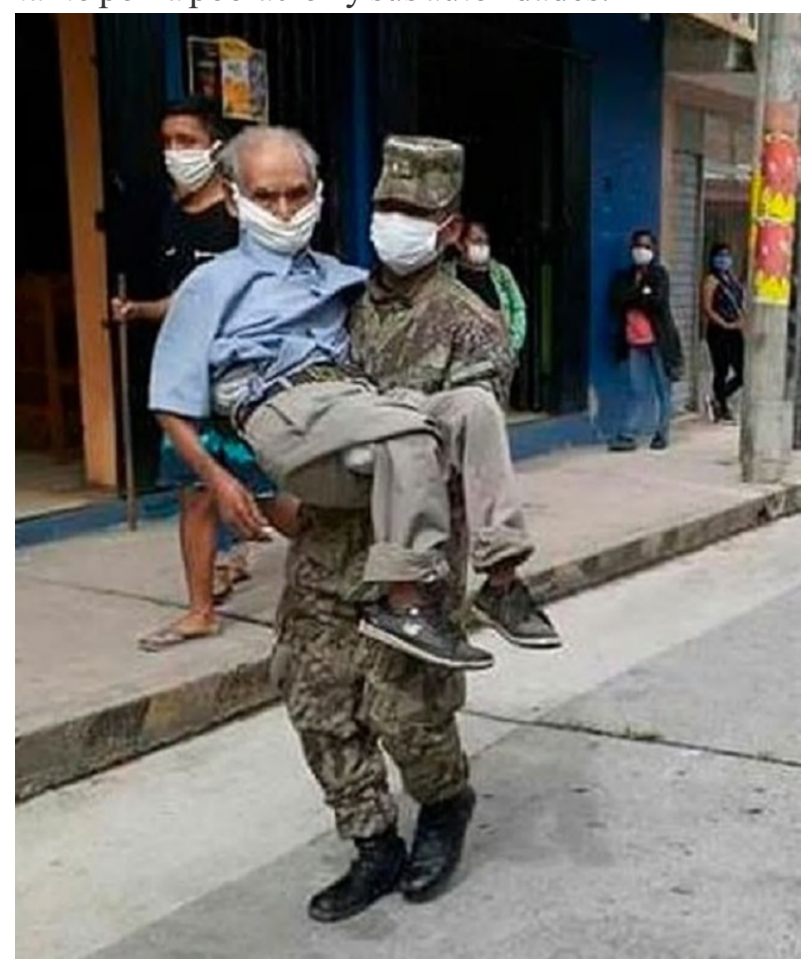

Figura 6: Adulto mayor es trasladado por soldado, durante la cuarentena por el COVID-19.

Fuente: Oficina de Informaciones del Ejército. 
Como consecuencia de la propagación mundial del COVID-19, que provocó en nuestro país la declaratoria a nivel nacional del Estado de Emergencia y del Aislamiento Social, no fueron ajenas las numerosas demandas por parte de la población requiriendo mayor presencia militar en distintos puntos de las ciudades donde primaba el desacato de aquellos por incumplir la cuarentena y contribuir con su actitud al contagio.

Frente a éste y otros reclamos, el Ejército vio necesario convocar, con el respaldo del poder político, a la reserva conformada por los licenciados que habían realizado el Servicio Militar Voluntario en los últimos años.

Al respecto, si hiciéramos una retrospectiva de qué hubiera ocurrido si prosperaba el proyecto mejorado para el Servicio Militar por sorteo u otra propuesta similar en el 2012-2013 ¿Hubiera tenido el Ejército un mayor número de efectivos militares que le permitiese un mejor control y apoyo a la población ante la reciente pandemia?

Como decían nuestros abuelos "más brazos voluntarios, hacen más rápido y menos pesado el trabajo". ¿Dónde estaban quienes se opusieron aquella vez al Servicio Militar por sorteo y que ahora ante la epidemia, reclamaban mayor presencia militar en las calles?

Queda claro que es la propia población junto con sus autoridades quienes entregan tanto los recursos materiales y humanos al Ejército para su instrucción y posterior empleo para la defensa y/o apoyo, ya no solo ante hipotéticos conflictos bélicos, sino también ante las amenazas de la propia naturaleza o de intereses humanos. Si los primeros no proporcionaron con anterioridad aquellos elementos ¿De dónde los sacarían y a último momento ante situaciones de crisis? Es allí donde aparece la importancia de desarrollar una visión prospectiva para tomar las mejores decisiones ante situaciones de crisis.

Con lo relatado en las páginas anteriores y frente a la epidemia aparecida recientemente, esperemos sacar lecciones y acciones como sociedad para el futuro mediato, después de lo experimentado como país a partir del 15 de marzo del 2020. Y en ese conjunto de acciones, será necesario tomar en cuenta la participación de los militares.

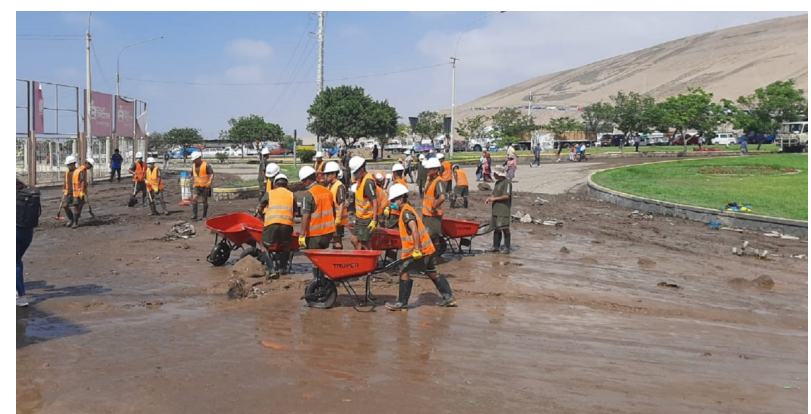

Figura 7: Limpieza del ingreso a la ciudad de Tacna, tras el deslizamiento de lodo y piedra, a comienzos del 2020. Fuente: Oficina de Informaciones del Ejército.

\section{CONCLUSIONES}

Las acciones desarrolladas por las Fuerzas Armadas del Perú, particularmente por el Ejército, en situaciones no militares que compromete el bienestar de la población, como se ha observado en los últimos 50 años, demuestran la necesidad de contar con esta fuerza, no solo para enfrentar hipotéticos conflictos internacionales o amenazas internas a futuro, sino también para el auxilio de la población siempre amenazada por los desastres naturales, sumándose ahora las pandemias y quizás, otros peligros en las siguientes décadas.

Las coyunturas políticas, las animadversiones o desconfianza entre el civil y el militar, o la indiferencia frente a la Defensa Nacional, no deben superponerse a las aspiraciones y precauciones que tenemos como país. Revisemos nuestra historia y veremos en ella que, sólo la unión entre el civil y el militar ha permitido superar las adversidades. El distanciamiento entre ambos, por el contrario, ha provocado trágicos episodios.

Ahora tocó a los militares combatir al lado de los profesionales de la salud y de la limpieza contra el COVID-19, quizás la primera pandemia del presente milenio, demostrando que en este nuevo siglo el Ejército de nuestro país, al igual que los del resto del mundo, actuará de manera multidimensional porque los nuevos retos y amenazas así lo exigen.

En nuestro caso, si no contásemos con las Fuerzas Armadas ¿Quién (es) hubiera (n) ocupado su lugar y asumido tan complejas misiones junto con el resto de profesionales involucrados frente a la pandemia? Debe quedar claro que lo militar ahora no es solo sinónimo de guerra, sino de "multipropósitos", que 
incluye el proteger a la población ante amenazas no bélicas, que son igual de peligrosas a una disputa armada.

Vale recordar nuevamente las palabras del historiador tacneño Jorge Basadre, quien al referirse al Ejército manifestaba: "Si el Perú subsiste, si no se disolvió o parceló es fundamentalmente por el Ejército [...] su presencia merece gratitud nacional" (Basadre, 1943, pp. 246-247).

El presente artículo no pretende ser una apología a lo militar; por el contrario, busca mostrar la otra cara de la moneda de su historia institucional tratada en las presentes páginas, contribuyendo en ampliar los aportes y debates académicos. Sabemos bien que, por un lado, han existido cuestionamientos sobre los actos de determinados personajes que han vestido el uniforme durante la historia republicana de nuestro país, que han sido calificados bajo títulos de "caudillismos", "militarismo", "dictaduras" e incluso de atentar contra los "derechos humanos" en tiempos más recientes, sobre los cuales existe abundante bibliografía y numerosos debates.

Sin embargo, no todo fue o es "oscurantismo" en la historia contemporánea del Ejército, como hemos apreciado en sus acciones, desde el terremoto en Yungay, hasta lo desarrollado recientemente ante el COVID-19.

Si no comenzamos a mostrar esa otra cara de la moneda de su historia militar y no se cuenta con la apertura por parte de la comunidad académica nacional ¿Cómo pretenderemos fortalecer las denominadas relaciones entre civiles y militares peruanas? La difusión histórica puede contribuir con ese propósito. Además, si no promovemos el debate académico entre ambos sectores de nuestra sociedad ¿Quiénes lo harán?

Para finalizar, apelando a la frase de Jorge Basadre citada anteriormente, en esta nueva coyuntura dominada por la preocupación y el temor, podríamos decir en el futuro "Si la población peruana sobrevivió a la pandemia, fue gracias al apoyo de sus Fuerzas Armadas, especialmente la brindada por el
Ejército". Los hechos relatados demuestran que el pasado inmediato y el futuro mediato, están unidos.

\section{REFERENCIAS}

Asociación Editorial Publicaciones Militares (2016). Ejército del Perú frente al fenómeno de El Niño. Revista Actualidad Militar, 500, 45-46.

Basadre, J. (1943). El mantenimiento y desarrollo de la nacionalidad. Revista de la Escuela Militar, XVIII, 209, 246-248.

Campos, S. (1983). El Ejército en la paz, siempre listo para ayudar. Revista Actualidad Militar, XX, 288, 7-10.

Canal N. Jefe del CC.FF.AA. sobre el coronavirus: Jóvenes, ahora cuiden a sus abuelos y padres. Recuperado el 1 de mayo 2020 https://canaln.pe/actualidad/jovenescuiden asusabuelosypadres/

Chiabra, R. (2010). La Seguridad Nacional en el siglo XXI: Escenarios, riesgos y amenazas. Políticas y estrategias. Lima: Magna ediciones.

Centro de Altos Estudios Nacionales (2010). Planteamientos doctrinarios y metodológicos del Desarrollo, Seguridady la Defensa Nacional. Lima, Perú: CAEN.

Comando de Reemplazos y Movilización del Ejército (2016). Servicio Militar Voluntario: Construyendo el futuro de nuestra nación. Lima, Perú: Ejército del PerúCOREMOVE.

Comisión Permanente de Historia del Ejército del Perú (2001). Historial de Unidades del Ejército del Perú. Lima, Perú: Oficina de Información del Ejército.

Comisión Permanente de Historia del Ejercito del Perú (2017). El Ejército del Perú frente a los desastres naturales. Lima, Perú: CPHEP.

Cuartel General del Ejército (1970). Terremoto, conmovedora solidaridad. Revista Actualidad Militar, 152.

El Comercio (2000). El siglo XX de El Comercio 1980-1989, tomo IX. Lima, Perú: El Comercio, Plaza Janés.

Ejercito del Perú (1983). Memoria Anual del 
Ejército. Lima, Perú.

Ejercito del Perú (1994). Memoria Anual del Ejército. Lima, Perú.

Espinoza, P. (2018). Rescate en la montaña. Revista Actualidad Militar, 515, 32-33.

Fagan, B. (2009). El gran calentamiento. Como influyó el cambio climático en el apogeo y caída de las civilizaciones. Barcelona, España: Gedisa Editorial.

Giesecke, A.; Silgado, E. (1981). Terremotos en el Perú. Lima, Perú: Ediciones Rickchay Perú.

Gómez, R. (2020, 21 de abril). Usar la metáfora de la guerra es perder el horizonte. La República, p. 21.

Klarén, P. (2011). Nación y sociedad en la historia del Perú. Lima, Perú: Instituto de Estudios Peruanos.

Kuroiwa, J. (1999). Prevención de desastres: Viviendo en armonía con la naturaleza. Lima, Perú: Editorial Bruño.

Machiavello, N. (2002). El príncipe. Lima, Perú: Ediciones Cultura Peruana.

Masterson, D. (2001). Fuerza Armada y sociedad en el Perú moderno. Un estudio sobre las relaciones civiles militares 1930-2000. Lima, Perú: Instituto de Estudios Políticos y Estratégicos.

Ministerio de Guerra-Estado Mayor General del Ejército. Orden General del Ejército. Lima, Perú, 24 de febrero de 1920.

O'Pheland, S. (2003). Familia y vida cotidiana en América Latina S. XVIII - XX. Lima, Perú: Pontificia universidad Católica del Perú.

Páez, J. (2013). Defensa y seguridad integral del Perú: Defensa de la población, biodiversidad, institucionalidad, territorio $e$ independencia. Lima, Perú: Impresiones OLGRAF.
Perez-Mallaina, P. (2001). Retrato de una Ciudad en crisis: La sociedad Limeña ante el movimiento sísmico de 1746. Lima, Perú: Pontificia Universidad Católica del Perú.

Salazar, F. (29 de marzo, 2020). Licencia para pegar. Recuperado de https://elcomercio.pe/opinion/columnistas/1 icencia-para-pegar-por-federico-salazarnoticia/

Taype, J. (2015). La ayuda bajó del cielo: La participación del Ejército en el terremoto de 1970. Revista Expresión Militar, 61-II, 6678.

Taype, J. (2015). Soldados constructores: Las Acciones Cívicas que consolidaron la Pacificación Nacional. Revista Expresión Militar, 62-III, 31-43.

Taype, J. (2017). El Ejército del Perú ante los desastres naturales. Revista Pensamiento Conjunto, $5, \mathrm{~N}^{\circ} 3,53-59$.

Taype, J. (2018). Vida y obra del General de División José del Carmen Marín Arista. Lima, Perú: Centro de Altos Estudios Nacionales.

Taype, J. (2019). Breve análisis sobre la presión mediática y la frustrada implementación del servicio militar por sorteo 2012-2013. Revista Expresión Militar, 78-III, 38-45.

Wicht, J; Rey de Castro, L (1998). Rehén voluntario. 126 días en la residencia del Embajador del Japón. Lima, Perú: Extra Alfaguara.

RAM. (1965). Ejército presta ayuda. Inundaciones en Tumbes. Revista Actualidad Militar, 10.

RAM. (1966). Catástrofe del 17 de octubre. Colaboración del Ejército. Revista Actualidad Militar, 8.

RAM. (1998). El Ejército del Perú frente al fenómeno de El Niño. Revista Actualidad Militar, 392, 14-18. 